\title{
A PRELIMINARYY TRIAL OF ETISUL IN TREATMENT OF LEPROSY PATIENTS
}

\author{
by H. MCGREGOR, M.B.E.,
}

Superintendent, Rajah Sir Charles Brooke Memorial Settlement, Kuching, Sarawak.

\section{Introduction}

The object of this trial was to gain first experience with Etisul as a practical drug in the treatment of patients in Sarawak. The patients chosen were 29 as follows: 6 Ibans, 9 Chinese, and 14 Malays; their ages were 18, 18, 20, 21, 22, 23, 23, 25, 25, 25, 26, 30, $32,34,35,37,38,38,39,39,40,44,45,47,49,50,53,61$ and 64 . There were 19 males and 10 females. The type of leprosy in all was some variation of lepromatous leprosy and secondary neural complications of a mild type occurred in 5 cases. Smears for acid-fast bacilli were taken at the beginning of treatment and continued being taken at 2-weekly intervals until the end of the course, which was at the end of 12 weeks. We used Etisul in the standard pack of 5 grammes of the cream containing the active drug. The drug was applied over a wide area of the body surface, usually the broad of the back, by gentle persistent inunction, preceded by the morning bath. After the inunction patients were required to rest for 2 hours before having another bath. The inunction was carried out by medical assistants under my supervision or that of responsible members of staff.

\section{Reaction of the Patients}

I think it is always worthwhile noting the personal reaction of patients to a new drug. Until recently the drug treatment of leprosy was slow and hence somewhat disappointing in results. In the days of the coming of DDS it was found almost everywhere in the world that patients reported that this drug had an effect on the disease which they felt in themselves. In the case of this present trial of Etisul our patients reported that they felt the new drug (Etisul) was having a good effect. They said they had a feeling of wellbeing and felt stronger. As regards the supposed bad odour of the drug they had no real objection perhaps because the garlic odour is a familiar thing in their environment. One patient objected to the rubbing which at the time to him was perhaps excessively vigorous, a point which assisted us to establish the rule of gentle and persistent inunction over a wide area rather than an inunction with perhaps too much vigour. There was one case which ceased treatment after 3 inunctions of Etisul owing to a sudden dermatitis, which however may well have been an allergic phenomenon due to a certain tree 
which is familiar in these parts. This tree is of the Mellanorrhoea group, known here as Rengas, and is sometimes inadvertently used as firewood. There was one other case who had to cease treatment after 10 inunctions after suddenly developing a severe reaction of the ENL type. Even at this point of stopping Etisul treatment her Bacillary Index had fallen from 0.5 to 0.33 , and subsequently she resumed treatment on DPT and has continued satisfactory progress so that 5 months after the cessation of Etisul and the occurrence of her reactional episode and adoption of treatment by DPT she has attained bacterial negativity. There was no other case of lepra reaction during the Etisul course.

\section{Previous or Concurrent Treatment}

Of the 29 patients treated with Etisul all had had previous treatment with DDS (in 3 cases with DPT) which was ceased at the time of the beginning of the Etisul course, so that Etisul was given alone for a period of 12 weeks. The average duration of treatment on standard drugs before applying Etisul was 9 months, during which time a certain amount of progress had been made. The Bacillary Index of an average of 1.18 fell to an average of 0.83 on the previous treatment by standard drugs.

\section{Results}

In all the 27 cases who completed the Etisul course we observed a moderate to marked clinical improvement. As regards the Bacillary Index the average of the groups at the beginning was 0.83 and, 12 weeks later, at the end of the course, was 0.34 . In effect there was no case which failed to achieve a good result in the end, and $62 \%$ achieved a satisfactory result in the 12 weeks. Of these cases only 3 are still positive, the Bacillary Indices being $0.4,0.2$ and 0.2 respectively.

(a) Clinical improvement was judged by the flattening of macules and nodules, and subsidence of diffuse thickening, and generally speaking this took place toward the end of the course. The patients themselves reported and indicated such improvement much earlier in the course, approximately at the end of the first 3 weeks. The decline of infiltration of the skin could be detected by changes in the reflection of light in the skin, so that it looked less turgid, and also by the appearance of fine wrinkling. This wrinkling also can be detected in the early stages of subsidence of infiltration by examination in a good light but becomes obvious in the later stages. No patient during the course, or in fact after it, showed any sign of acute leprotic neuritis. A marked feature of all the patients in the trial was the considerable improvement in bearing and fitness to outward observation. The patients looked well and it was noticeable that they carried themselves as if they were normal beings in the best 
8

$$
\text { Before }
$$

After

7

6

Group II.

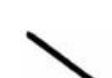

Group I.

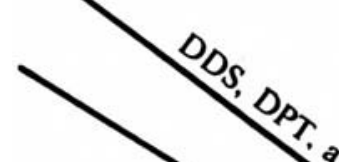

5

GruPH I. Lesion Index before and afier irearment.

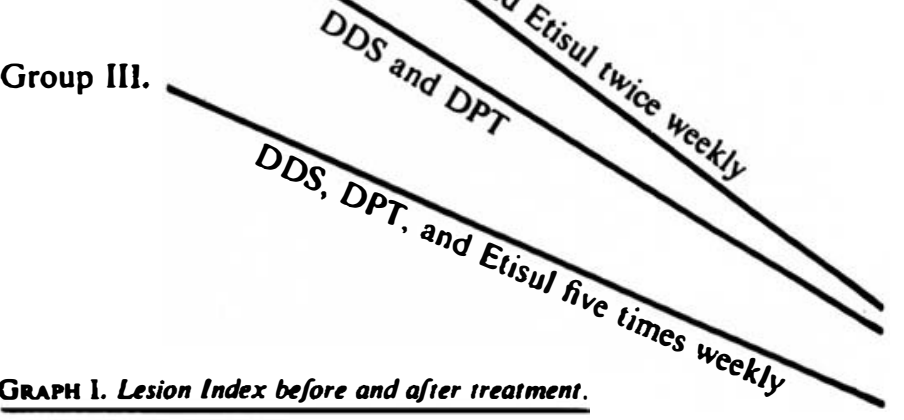

B.1.

30

\section{ET IS UL}

2

10 


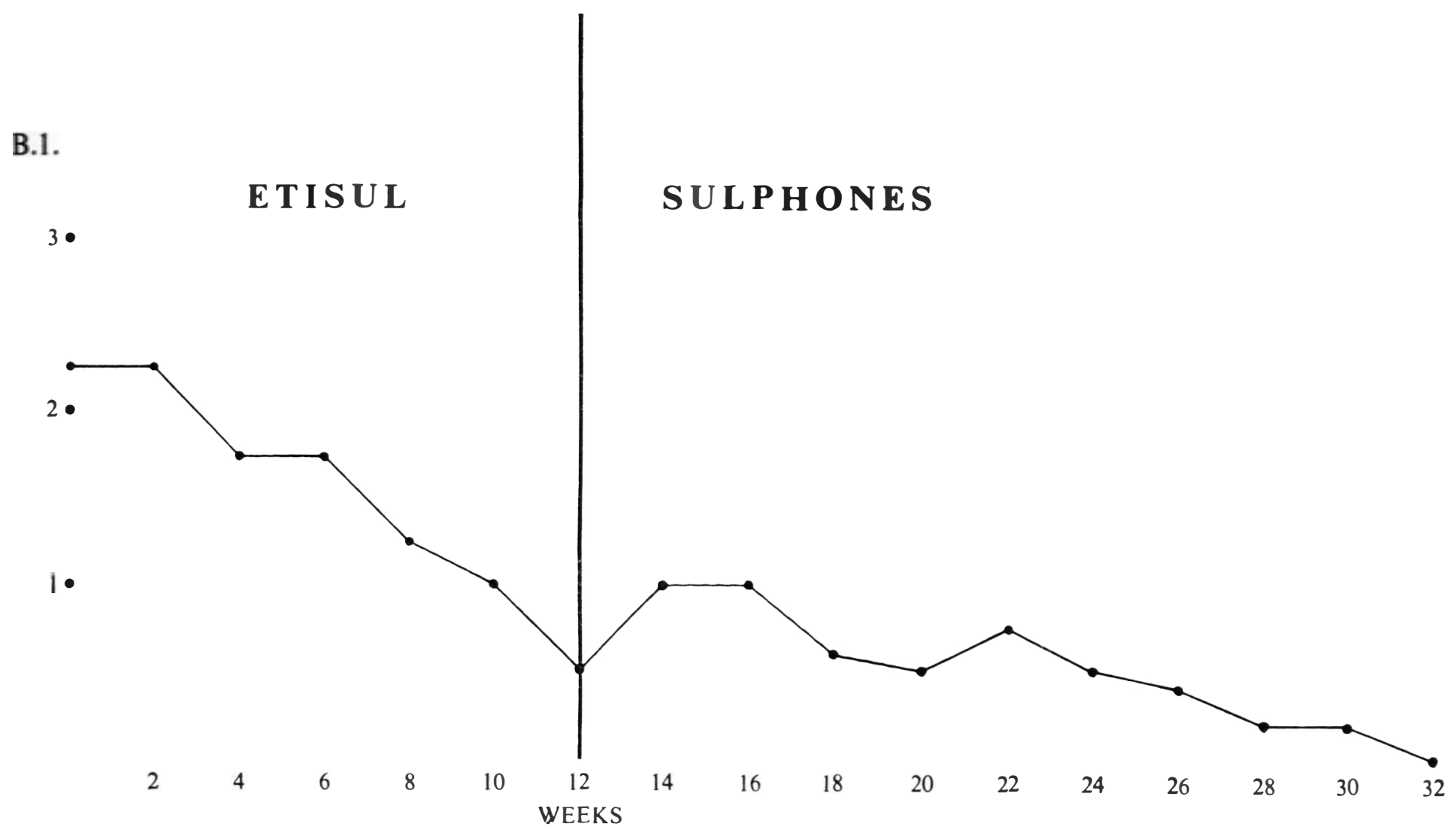




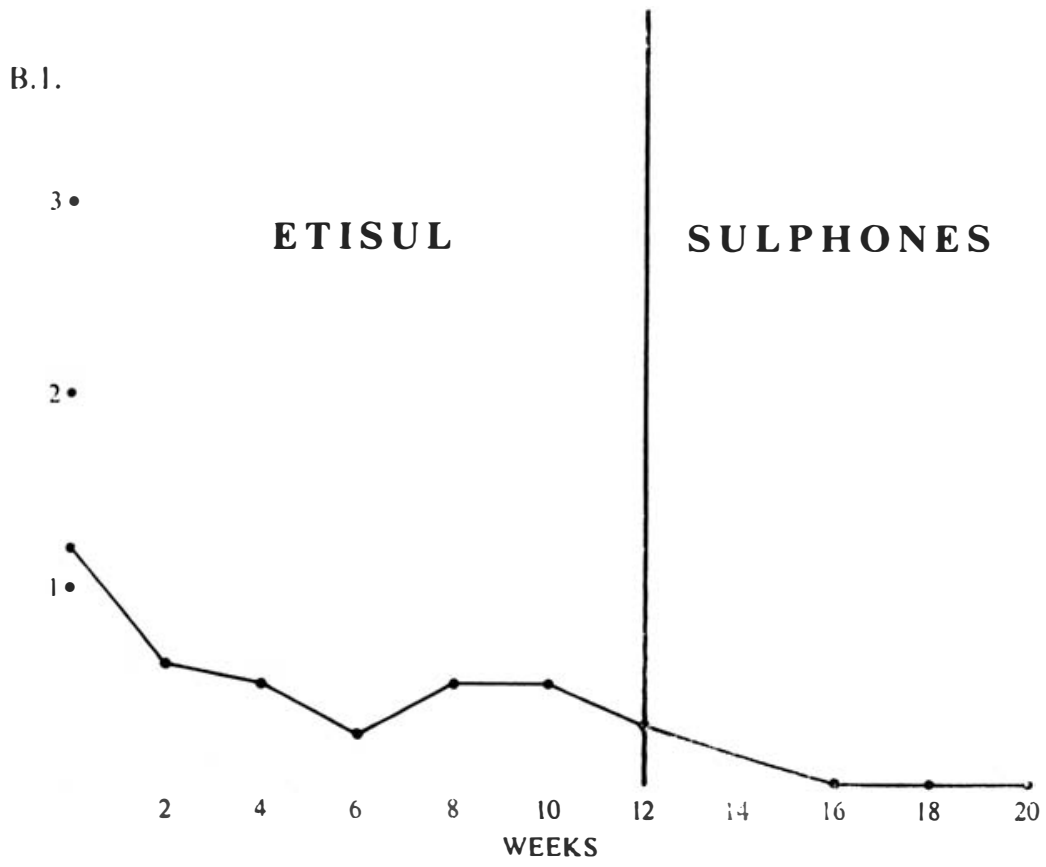

of health. To our observation this finding has not been seen under any previous leprosy treatment in such a short time. It may of course in part be a psychological impact, but the physical signs which formed part of it were very definite. Of the patients concerned 13 were employed in jobs round and about the leprosarium and continued their work satisfactorily, and the remainder continued their normal work in the daily life of the Settlement. We can confirm the report of Ross, Telfer and Hilton (Leprosy Review of October 1960) that there was an improvement in the oedema of hands and feet which often accompanies lepromatous leprosy, but our cases were mild and few.

We were fortunate in having a visit from Dr. James Ross Innes, Medical Secretary of the British Leprosy Relief Association and Secretary-General of the International Leprosy Association (10th to 26th October 1960), and were able to show the patients to him. He allows me to state that, in his opinion, this group of patients showed unmistakeable evidence of a drug active in leprosy in a relatively short time for anti-leprosy drugs. He has suggested to us that we proceed to a controlled trial of the drug and this we hope to do.

\section{Summary}

Patients, 29 in number, subjects of lepromatous leprosy who had previously been treated with standard drugs were subjected to a 
trial of Etisul for a duration of 12 weeks. The results have been encouraging, showing a clinical and bacteriological improvement in the period well beyond the level of our experience of other drugs. We found no difficulties in obtaining the co-operation of the patients and have found that a widespread, gentle, and persistent body inunction for 20 minutes or more is practical and efficient. The odour caused no difficulty. There is much more difficulty following crude and rough inunction. We hope to proceed to a controlled trial as the next step. We found that certain cases who apparently had poor results at the end of the trial went on to a satisfactory result when placed on DDS or DPT. It appears from this that the association of Etisul with one or more of the standard drugs is important. We think that Etisul can readily be used not only in hospital conditions but also in district work.

\section{Acknowledgments}

Thanks are due to members of staff for their work and assistance throughout the trial.

Thanks are also due to the Director of Medical and Health Services, Sarawak, for permission to publish. 